\title{
COMUNICAÇÃOCIENTÍFICA
}

\section{GERMINAÇÃO DE SEMENTES E DESENVOLVIMENTO INICIAL DE PLÂNTULAS DE ACHACHAIRU ${ }^{1}$}

\author{
WILSON BARBOSA ${ }^{2 *}$, EDVAN ALVES CHAGAS ${ }^{3}$, LEILA MARTINS $^{4}$, RAFAEL PIO $^{5}$, \\ MARIA LUIZA SANT'ANNA TUCCI ${ }^{6}$, FABIANE APARECIDA ARTIOLI $^{7}$
}

RESUMO - O achachairu (Garcinia sp), fruta largamente produzida na Bolívia, vem sendo comercializado no Brasil há vários anos. $\mathrm{O}$ fruto é globoso-oblongo, de polpa branca, suculenta e textura mucilaginosa e de sabor doce-acidulado equilibrado ( ${ }^{\circ} \mathrm{Brix} 15 \mathrm{e} \mathrm{pH}$ $4,1)$. Devido ao crescente interesse em seu cultivo no Brasil, pesquisaram-se a germinação das sementes e o desenvolvimento das plântulas durante os primeiros 12 meses após sua emergência. As sementes, extraídas de frutos bem maduros, foram postas a germinar em duas situações: 1) ambiente controlado em estufa tipo B.O.D., sob as temperaturas de 25 e $30^{\circ} \mathrm{C}$, fotoperíodo de 16 horas e irradiância de $32 \mu \mathrm{mol} . \mathrm{m}^{-1} \cdot \mathrm{s}^{-1}$, e 2) ambiente de temperatura não-controlada: 3) B.O.D, cuja temperatura oscilava entre 20 e $30^{\circ} \mathrm{C}$, e 4 ) sob temperatura ambiente de laboratório $\left(25 \pm 2{ }^{\circ} \mathrm{C}\right)$. O melhor resultado foi obtido na temperatura constante de $30^{\circ} \mathrm{C}$, com germinação de $92 \%$ e índice de velocidade de germinação (IVG) de 0,255. Quando germinada em ambiente de laboratório, a germinação das sementes mostrou-se baixa (30\%), com IVG de 0,015. O desenvolvimento das plântulas em casa de vegetação ocorreu de forma bastante lenta, principalmente nas primeiras semanas após a emergência. O primeiro par de folhas surgiu após três semanas da emergência das plântulas, quando essas mediam $8 \mathrm{~cm}$ em média. A partir do oitavo mês de desenvolvimento, as plântulas emitiram várias ramificações laterais a partir da porção mediana para a região apical.

Termos para indexação: frutífera, propagação, Clusiaceae, Garcinia sp.

\section{SEEDS GERMINATION AND SEEDLINGS EARLY DEVELOPMENT OF ACHACHAIRU}

ABSTRACT - The achachairu (Garcinia sp), a fruit widely grown in Bolivia, has been commercialized in Brazil for many years. The fruit is globular-oblong shaped, with a white succulent pulp, mucilaginous texture and a well balanced sweet-acid flavor $\left({ }^{\circ} \mathrm{Brix} 15 ; \mathrm{pH}\right.$ 4.1). Due to the increasing interest in its cultivation in Brazil, this work was carried out aiming to study the seeds germination and seedling development throughout the first 12 months after seed emergence. The seeds, after being extracted from full ripe fruits were placed in a B.O.D. type chamber, under the following temperatures: $25,30,20-30^{\circ} \mathrm{C}$, as well as under room temperature $\left(25 \pm 2{ }^{\circ} \mathrm{C}\right)$. The best result was given by the steady temperature of $30^{\circ} \mathrm{C}$, with a germination of $92 \%$ and a germination speed index (GSI) of 0,255 . At room temperature, seeds germination was low (30\%), with a GSI of 0,015 . Seedling development at greenhouse conditions was very slow mainly throughout the first weeks post emergence. The first pair of leaves appeared 25 days after seedling emergence, when seedlings averaged $8 \mathrm{~cm}$. From the eighth month on, many lateral branches were burst out, from the seedling medial portion towards the apical one.

Index Terms: fruit tree, propagation, Clusiaceae, Garcinia sp.

O achachairu (Garcinia sp), da família Clusiaceae, é uma fruta bastante apreciada na Bolívia, onde há projetos de desenvolvimento da cadeia produtiva para o atendimento de produtores do município de Ayacucho, Santa Cruz (FDTA Trópico Húmedo, 2005). Os frutos têm massa de 30 gramas e são globoso-oblongos, semelhantes à nêspera (Eriobotrya japonica Lindl.). Externamente, os frutos são amarelo-alaranjados, com casca grossa, lisa, firme e resistente. A polpa, não aderente à casca, é branca, suculenta e de textura mucilaginosa, representando $1 / 3$ da massa média do fruto. O sabor, que lembra um pouco o do araçá, é bem agradável e doce-acidulado equilibrado, com ${ }^{\circ}$ Brix 15 e pH 4,1 (Barbosa \& Artioli, 2007).

Com a recente mudança do gênero Rheedia para Garcinia (Liogier, 1986), estabeleceu-se certa confusão na nomenclatura das dezenas de espécies conhecidas. Isso porque, muitos autores ainda usam o termo Rheedia para algumas frutíferas nativas e exóticas, existentes em várias regiões tropicais mundiais. A fruta

${ }^{1}$ (Trabalho 095-07). Recebido em 10-04-2007. Aceito para publicação em: 14-12-2007. Pesquisa pertencente ao Projeto: "Introdução, quarentena, propagação e avaliação de espécies e cultivares de frutíferas". Trabalho realizado com apoio financeiro do CNPq.

${ }^{2}$ Pesquisador Científico (PqC), Centro Experimental Central, Instituto Agronômico (IAC), Caixa Postal 28, CEP 13001-970, Campinas-SP. Com bolsa de produtividade em pesquisa do CNPq. *Autor para correspondência. E-mail: wbarbosa@iac.sp.gov.br

${ }^{3} \mathrm{PqC}$, Centro APTA Frutas, IAC, Av. Luis Pereira dos Santos, 1500, 13214-820, Jundiaí-SP.

${ }^{4}$ Eng $^{\text {a }}$. Agr ${ }^{\mathrm{a}}$. Departamento de Sementes, Mudas e Matrizes, CATI, CP 962, CEP 13070-178, Campinas-SP.

${ }_{5}^{5} E_{n}{ }^{\circ}$. Agrônomo, D.Sc., Professor Adjunto da Universidade Estadual do Oeste do Paraná - UNIOESTE. Rua Pernambuco, n 1777 , Caixa Postal 1008, Centro, 85960-000, Marechal Cândido Rondon-PR. Bolsista de Produtividade em Pesquisa do CNPq.Autor para correspondência:rafaelpio@hotmail.com. ${ }^{6} \mathrm{PqC}$, Centro APTA Horticultura, IAC. E-mail: tucci@iac.sp.gov.br.

${ }^{7}$ Graduanda em Ciências Biológicas, Universidade Federal de Alfenas (UNIFAL), Rua Gabriel Monteiro da Silva, 714, CEP 37130-000, Alfenas-MG. Email: fabiane_art@yahoo.com.br. 
mais famosa desse gênero, talvez, seja o mangostão ( $G$. mangostana L.), originada no trópico asiático. Outras espécies de Garcinia, além de sua importância farmacológica (Luzzi et al., 1997; Guimarães et al., 1997; Rodrigues et al., 2000; Santos et al., 1999; 2001), também fazem parte da alimentação da população da região Amazônica, onde os frutos são bastante abundantes.

Em levantamento recente sobre as pesquisas nacionais envolvendo Garcinia (Rheedia), Barbosa \& Artioli (2007) verificaram que a grande maioria dos artigos publicados em periódicos diz respeito à caracterização química e aos efeitos terapêuticos dos frutos e folhas. Pelos autores brasileiros, apenas as espécies Rheedia gardneriana Planch. \& Triana e $R$. acuminata (Ruiz et Pav.) Plachon et Triana, Garcinia cambogia, G. mangostana, G. macrophylla, G. gardneriana, G. cochinchinensis e G. multiflora foram citadas. Os autores observaram que somente $10 \%$ dos artigos relatavam pesquisas agronômicas, especialmente propagação seminífera e caracterização morfológica de sementes e plântulas (Nascimento et al., 2002; Oliveira et al., 1996). R. gardneriana e R. acuminata são nativas da Amazônia e pertencem agora ao gênero Garcinia. Esse material encontra-se disseminado em todo o território nacional, principalmente G. gardneriana (Santos et al., 1999), cujo fruto é conhecido no Pará como bacuripari. Segundo Nascimento et al. (2002), G. acuminata (bacurizinho) é raramente cultivada devido ao baixo rendimento em polpa, mas pode ser usado como porta-enxerto ananicante de outras frutíferas do gênero, a exemplo do mangostão. Contudo, sabe-se que, para a maioria das espécies, a propagação seminífera constitui-se num processo natural e mais importante de disseminação e perpetuação das espécies. Entretanto as germinações de sementes de muitas espécies apresentam diferentes potencias de germinação. Enquanto as sementes de muitos vegetais germinam tão logo sejam colocadas em condições de solo e ambiente favorável, outras, embora vivas, deixam de germinar mesmo quando submetidas a condições quase ideais. Com relação aos aspectos fisiológicos, estudos realizados com espécies do gênero Garcinia concluíram que muitas dessas espécies são do tipo recalcitrante (Roberts e Ellis, 1973; Roberts e King, 1980; Chin, 1989) e, por esse motivo, perdem a viabilidade rapidamente (Winters e Rodrigues-Colon, 1953, citado por Nascimento, 2001). Devido à boa qualidade organoléptica dos frutos e ao crescente interesse pelo cultivo do achachairu no Brasil, foram pesquisados a germinação das sementes sob diferentes condições e temperaturas e o desenvolvimento inicial das plântulas em casa de vegetação.

Os frutos frescos do achachairu, com oito dias de colhidos, foram adquiridos em março de 2005 na CEAGESP, sendo esses provenientes de cultivos na região de Recife-PE. Os frutos maduros, após devidamente caracterizados, foram armazenados a $5{ }^{\circ} \mathrm{C}$, por uma semana, em geladeira industrial com $80 \%$ de umidade. Posteriormente, extraíram-se as sementes, que foram lavadas em água corrente e secas à sombra, por 24 horas. As sementes foram postas a germinar, sob vermiculita, em duas situações: 1) ambiente controlado em estufa tipo B.O.D., sob as temperaturas de 25 e $30{ }^{\circ} \mathrm{C}$, fotoperíodo de 16 horas e irradiância de $32 \mu \mathrm{mol} \cdot \mathrm{m}^{-1} \cdot \mathrm{s}^{-1}$, e 2) ambiente de temperatura não- controlada em B.O.D, cuja temperatura oscilava entre 20 e $30^{\circ} \mathrm{C}$ e sob temperatura ambiente de laboratório $\left(25 \pm 2{ }^{\circ} \mathrm{C}\right)$, constituindo-se um total de quatro tratamentos. As avaliações, feitas durante 90 dias, forneceram dados que foram expressos em porcentagem de plântulas normais, segundo critérios estabelecidos por BRASIL (1992). Foram usadas 60 sementes por tratamento, em quatro repetições de 15 unidades cada. $\mathrm{O}$ índice de velocidade de germinação (IVG) foi calculado com base em Marcos Filho et al. (1987), contando-se o número de indivíduos emersos a cada dois dias, até 90 dias após instalação do teste de germinação. Para avaliar o desenvolvimento inicial das plântulas, instalou-se um segundo experimento. Neste caso, as sementes foram semeadas em bandejas de isopor contendo 128 células preenchidas com vermiculita. Após 40 dias sob ambiente de estufa tipo B.O.D., a $28{ }^{\circ} \mathrm{C}$, as sementes germinadas foram transplantadas em vasos $(30 \times 20 \mathrm{~cm})$, contendo substrato previamente preparado (Solomax ${ }^{\circledR}$, terra, areia e esterco de galinha) e mantidas em casa de vegetação dotada de irrigação automatizada (aspersão).

O delineamento experimental usado foi o inteiramente casualizado, com quatro repetições, sendo cada uma constituída de cinco plantas. Foram realizadas quatro avaliações, sendo a primeira no momento do transplantio, e as demais, aos 4; 8 e 12 meses. As variáveis analisadas foram: a altura da planta, o diâmetro do caule a $5 \mathrm{~cm}$ acima da superfície do solo e o número de folhas das plântulas. Os dados obtidos foram submetidos à análise de variância pelo teste $\mathrm{F}$, sendo que as médias dos valores qualitativos foram comparadas pelo teste de Tukey, e os quantitativos, submetidos à regressão polinomial $(\mathrm{P}<0,05)$, de acordo com as indicações de Gomes (2000), usando-se o Sistema para Análise de Variância - SISVAR (Ferreira, 2000).

A análise de variância para as variáveis analisadas está apresentada na Tabela 1 . Houve diferença significativa, a $1 \%$ de probabilidade, para todas as variáveis testadas.

Verificou-se que $65 \%$ dos frutos continham apenas uma semente grande. No restante da amostra, foram observadas de 2 a 3 sementes médias e pequenas por fruto. Sob ambiente de B.O.D., a $25^{\circ} \mathrm{C}$ e a $30^{\circ} \mathrm{C}$, as sementes iniciaram a germinação mais rapidamente, cerca de dez dias antes dos demais tratamentos (Tabela 2), ou seja, aproximadamente 15 dias após a semeadura. Esses dados estão de acordo com os encontrado por Müller et al. (1995), os quais observaram que, em condições favoráveis de temperatura e umidade, as sementes de mangostão germinam entre onze e quinze dias após a semeadura. As porcentagens de plântulas normais foram de 90 e $92 \%$ para as temperaturas de 25 e $30^{\circ} \mathrm{C}$, respectivamente, não apresentando diferença significativa entre elas. Esses resultados mostram que, bem acondicionadas, as sementes de Achachairu permanecem viáveis e com excelente porcentagem de germinação mesmo quando, após o armazenamento, sejam submetidas a procedimentos adequados de germinação. Müller et al. (1991), estudando o potencial de armazenamento de sementes de espécies da mesma família, demonstraram que as sementes de mangostão podem ser armazenadas no fruto por períodos de até 35 dias, acondicionadas em sacos de plástico, sem que ocorram danos à qualidade fisiológica. Entretanto, quando se avaliou o IVG, o maior resultado 
$(0,255)$ foi observado quando as sementes foram submetidas à temperatura de $30^{\circ} \mathrm{C}$, seguida por aquelas submetidas a $25^{\circ} \mathrm{C}$ (Tabela 2). O índice de velocidade de germinação está relacionado com o vigor da semente (Nascimento et al., 2001). Neste caso, verificou-se que as sementes, quando submetidas a $30^{\circ} \mathrm{C}$ de temperatura, apresentaram maior vigor, sendo esta a temperatura ótima de germinação de sementes de Garcínia sp., nas condições em que o trabalho foi realizado.

As sementes submetidas às temperaturas alternadas de 20-30 ${ }^{\circ} \mathrm{C}$ e em condições de laboratório germinaram cerca de 30 dias após colocadas na estufa B.O.D. A menor porcentagem de germinação ocorreu quando as sementes foram submetidas às condições de ambiente de laboratório, onde se constatou, que a maioria das sementes $(70 \%)$ estavam mortas após 90 dias (Tabela 2).

Em casa de vegetação, verificou-se um desenvolvimento bastante lento das plântulas, principalmente nas primeiras semanas após a emergência. Essa fase coincidiu com o período de inverno, em que as médias das temperaturas mínimas e máximas em Campinas-SP, foram, respectivamente, de $16^{\circ} \mathrm{C}$ e $24^{\circ} \mathrm{C}$. O primeiro par de folhas opostas (metáfilo) surgiu após cerca de 25 dias da emergência das plântulas. Nascimento et al. (2001), estudando o efeito da fermentação na germinação de sementes de mangostão, constaram que a germinação teve início entre nove e doze dias, e com término entre 19 e 26 dias após a semeadura. A partir do oitavo mês de desenvolvimento (no verão), as plântulas emitiram várias ramificações laterais, em sua porção centro-apical. Para as três variáveis analisadas (altura de plântulas, diâmetro de caule e número de folhas das plântulas), observou-se um crescimento linear em função do tempo avaliado.

As plântulas apresentaram um desenvolvimento pouco satisfatório, atingindo somente $25 \mathrm{~cm}$ de altura (Figura A) e diâmetro (3 mm) ao final dos 12 meses (Figura B). Nesse período, as plântulas apresentaram 20 pares de folhas cada, constituindose num adequado enfolhamento para o período (Figura $\mathrm{C}$ ).

TABELA 1- Resumo da análise de variância para germinação, sementes mortas, índice de velocidade de germinação (IVG), altura da planta, diâmetro do caule (mm) e número de folhas (NF) de plântulas de Garcinia sp. Instituto Agronômico (IAC), 2007.

\begin{tabular}{|c|c|c|c|c|c|c|c|}
\hline \multirow{2}{*}{$\begin{array}{l}\text { Fontes de } \\
\text { variação }\end{array}$} & \multirow{2}{*}{ G.L } & \multicolumn{6}{|c|}{ Quadrado médio } \\
\hline & & $\begin{array}{c}\text { Germinação } \\
(\%)\end{array}$ & $\begin{array}{c}\text { Sementes Mortas } \\
(\%)\end{array}$ & IVG & $\begin{array}{l}\text { Altura da } \\
\text { planta (cm) }\end{array}$ & $\begin{array}{l}\text { Diâmetro do } \\
\text { caule (mm) }\end{array}$ & $\begin{array}{l}\text { Número de } \\
\text { folhas (un) }\end{array}$ \\
\hline Tratamento & 3 & $3364.000000 * *$ & $3364.000000^{* *}$ & $0.039683^{* *}$ & $380.750000^{* *}$ & $600.229167^{* *}$ & $350.166667^{* *}$ \\
\hline Resíduo & 12 & 24.666667 & 10.000000 & 0.000042 & 3.291667 & 0.937500 & 11.125000 \\
\hline$\overline{C . V .}$ & 15 & 6,85 & 11,50 & 5,25 & 15,28 & 5,55 & 35,11 \\
\hline
\end{tabular}

** significativo a $1 \%$ de probabilidade, segundo o teste $\mathrm{F}$.
TABELA 2- Porcentagem de germinação, sementes mortas e índice de velocidade de germinação (IVG) das sementes de Garcinia sp. Instituto Agronômico (IAC), 2007.

\begin{tabular}{lccc}
\hline \multirow{2}{*}{ Temperaturas } & \multicolumn{3}{c}{ Variáveis analisadas } \\
\cline { 2 - 4 } & $\begin{array}{c}\text { Germinação } \\
(\%)\end{array}$ & $\begin{array}{c}\text { Sementes } \\
\text { mortas }(\%)\end{array}$ & IVG \\
\hline $25^{\circ} \mathrm{C}$ & $90 \mathrm{a}$ & $10 \mathrm{~b}$ & 0,127 \\
$30^{\circ} \mathrm{C}$ & $92 \mathrm{~b}$ & $8 \mathrm{~b}$ & $0,255 \mathrm{a}$ \\
$20-30^{\circ} \mathrm{C}$ & $78 \mathrm{a}$ & $22 \mathrm{~b}$ & $0,097 \mathrm{~b}$ \\
ambiente & $30 \mathrm{~b}$ & $70 \mathrm{a}$ & $0,015 \mathrm{c}$
\end{tabular}

* Médias seguidas da mesma letra em minúsculo na coluna não diferem significativamente entre si, pelo teste de Tukey, ao nível de 5\% de probabilidade.

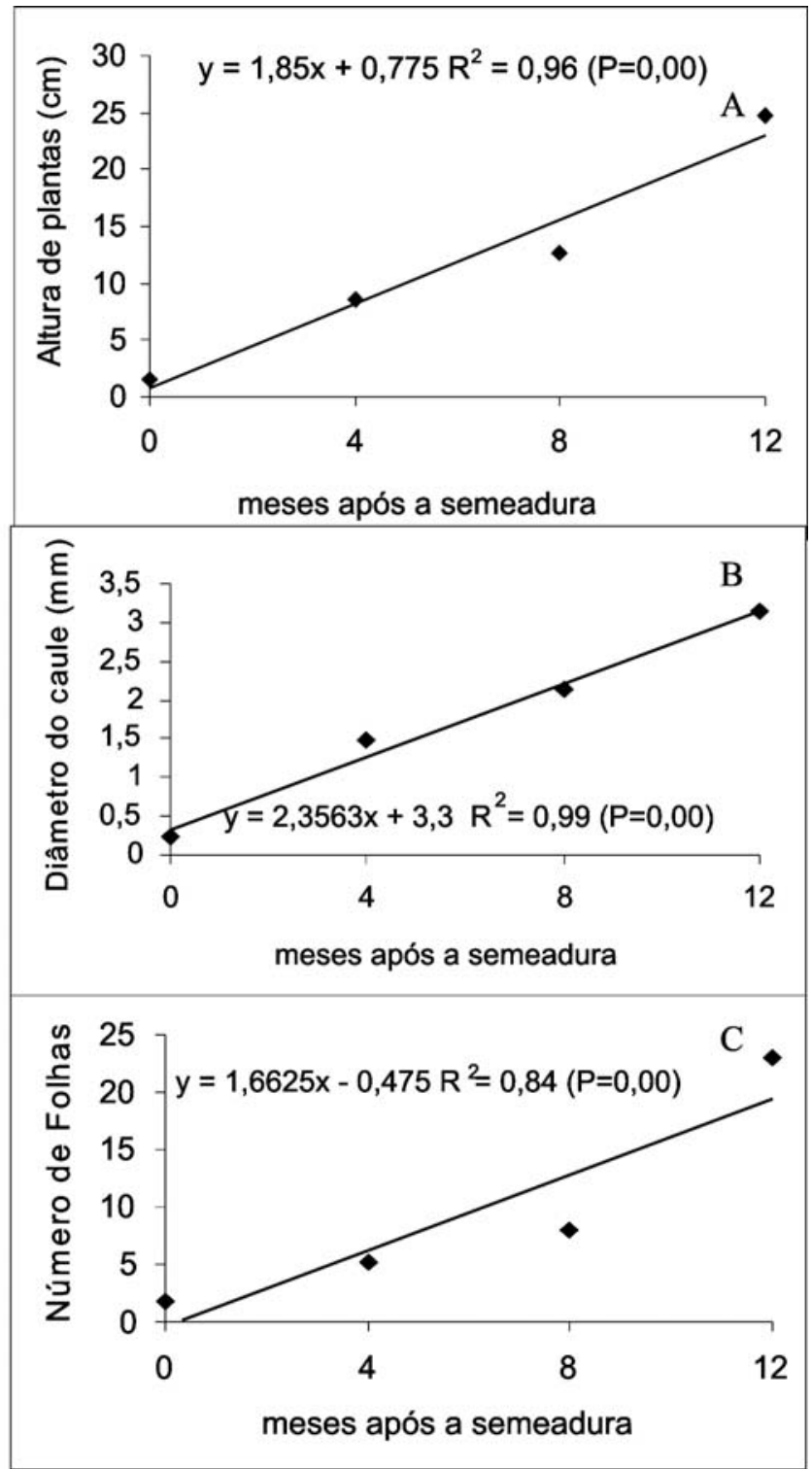

FIGURA 1- Altura de plântulas (A), diâmetro do caule (B) e número de folhas $(\mathrm{C})$ de Garcinia sp analisadas aos 4; 8 e 12 meses após a emergência. Instituto Agronômico (IAC), 2007. 


\section{AGRADECIMENTOS}

Os autores agradecem a Hugo Tenório a cessão das frutas e às estagiárias Maraísa Freitas de Moraes Rosa, Tânia Misae Watanabe e Marcela Mariano Mosken, bolsistas PIBIC/CNPq, o manuseio e o controle da germinação das sementes e às medições das plântulas em casa de vegetação.

\section{REFERÊNCIAS}

BARBOSA, E.; ARTIOLI, F. A. A fruta achachairu. Disponível em: <http://www.infobibos.com/Artigos/2007_1/achachairu/ index.htm>. Acesso em: 26 mar. 2007.

BRASIL, Ministério da Agricultura e Reforma Agrária. Regras para análise de sementes. Brasília: SNDA/DNDV/CLAV, 1992. 365 .

CHIN, H.F. Recalcitrant seeds. Taipei: Food \& Fertilizer Technology Center, 1989. 16p. (Extension Bulletin, 288).

FDTA - Trópico Húmedo (Fundación Para el Desarrollo Tecnológico Agropecuario y Forestal del Trópico Húmedo). Mejoramiento del sistema de producción, selección y comercialización del cultivo de achachairú (rheedia spp) en el municipio de ayacucho (Porongo), Santa Cruz. 2005. 46p. Disponível em: $<$ http://www.tropico.org.bo/Lineabase/Línea de Base Achachairu.pdf $>$. Acesso em: 12 jan. 2007.

FERREIRA, D. F. Análise estatística por meio do SISVAR (Sistema para Análise de Variância) para Windows versão 4.0. In: REUNIÃOANUALDAREGIÃOBRASILEIRADASOCIEDADE INTERNACIONAL DE BIOMETRIA, 45., 2000, São Carlos. Anais... São Carlos: UFSCar, 2000. p. 255-258.

GOMES, F. P. Curso de estatística experimental. 14. ed. Piracicaba: USP/ESALQ, 2000. 477 p.

GUIMARÃES, C. L. ; LUZZI, R. ; VERDI, L.G ; SIMIONATTO, E.L.; DELLE MONACHE, F.; YUNES, R.A.; FLORIANI, A..E.O ; CECHINEL FILHO, V . Isolation of biflavonoids with analgesic activity from Rheedia gardneriana leaves. Phytomedicine, Chicago, v. 4, p. 141-144, 1997.

LIOGIER, H. A. Novitates antillanae. XII. Phytologia, Hunstsville, v. 61, p.353-360, 1986.

LUZZI, R.; GUIMARAES, C. L.; VERDI, L. G.; SIMIONATTO, E. L.; DELLE-MONACHE, F.; YUNES, R. A.; FLORIANI, A. E. O.; OLIVEIRA, A. E.; CECHINEL FILHO, V. Isolation of biflavonoids with analgesic activity from Rheedia gardneriana leaves. Phytomedicine, Chicago, v. 4, n. 2, p. 141-144, 1997.
MARCOS FILHO, J.; CÍCERO, S.M.; SILVA, W.R. Avaliação da qualidade das sementes. Piracicaba: FEALQ, 1987.

MÜLLER, C.H.; FIGUEIREDO, F.J.C.; MÜLLER, N.R.M. Armazenamento de sementes de mangostão. Belém: EMBRAPACPATU, 1991. 15p. (Circular Técnica, 58).

MÜLLER, C.H.; FIGUEIREDEO, F.J.C.; NASCIMENTO, W.M.O. do; CARVALHO, J.E.U. de; STEIN, R.L.B.; SILVA, A. de B.; RODRIGUES, J.E.L.F. A cultura do mangostão. Brasília: EMBRAPA-SPI, 1995. 56p. (Coleção Plantar, 28).

NASCIMENTO, W.M.O.; TOMÉ, A.T.; CARVALHO, J.E.U.; MÜLLER, C.H. Comportamento fisiológico de sementes de mangostão (Garcinia mangostana L.) submetidas a diferentes períodos de fermentação da polpa. Revista Brasileira de Fruticultura, Jaboticabal, v.23, n.3, p.735-737, 2001.

NASCIMENTO, W. M. O.; CARVALHO, J. E. U.; MÜLLER, C.H. Caracterização morfológica da semente e da plântula de bacurizinho (Rheedia acuminata (Ruiz et Pav.) Planchon et Triana - Clusiaceae. Revista Brasileira de Fruticultura, Jaboticabal, v.24, n.2, p.555-558, 2002.

OLIVEIRA, I. V. de Morais; ANDRADE, R. A.; MARTINS, A. B. G. Influência do tamanho-peso da semente na precocidade de emergência de bacuripari (Rheedia gardneriana). Caatinga, Mossoró, v.19, n.4, p.387-390, 2006.

RODRIGUES, C.A.; OLIVEIRA,A. E.; SILVA,A. F. S.; CECHINEL FILHO, V.; GUIMARAES, C. L.; YUNES, R. A.; DELLEMONACHE, F. A comparative study of stationary phase for separation of biflavonoids from Rheedia gardneriana using column chromatography. Zeitschrift Fuer Naturforschung Section C Journal of Biosciences, Tuebingen, v.55, n.7-8, p.524$527,2000$.

SANTOS, M. H.; NAGEM, T. J.; OLIVEIRA, T. T.; OLIVEIRA, J. R.; LIMA, R. D.; QUEIROZ, M. E. L. R.; MIRANDA, L. C. G. Efeito de constituintes químicos extraídos do fruto de Rheedia gardneria (bacuparí) sobre bactérias fitopatogênicas. Revista Brasileira de Ciências Farmacêuticas, São Paulo, v.35, n.2, p.297-30, 1999.

SANTOS, M. H.; NAGEM, T. J.; STRINGHETA, P. C.; OLIVEIRA, T. T.; VIEIRA FILHO, S. A. Estudo preliminar da atividadei e antiinflamatória apresentada por substâncias isoladas de Vismia latifolia e de Rheedia Gardneriana. Revista Brasileira de Toxicologia, Ribeirão Preto, v.14, n.2, p.93, 2001. 